\title{
Quality assessment of compost from Centralized windrow composter (CWC) and Source segregate automatic vessel composter (AVC) at Hyderabad city in India
}

\author{
Anil Kurmana \\ Department of Environmental Science, GITAM Institute of Science, GITAM (Deemed to be \\ University), Visakhapatnam-530045 (Andhra Pradesh), India \\ N. Srinivas* \\ Department of Environmental Science, GITAM Institute of Science, GITAM (Deemed to be \\ University), Visakhapatnam-530045 (Andhra Pradesh), India \\ *Corresponding author. Email: snamudur@gitam.edu
}

\section{Article Info}

https://doi.org/10.31018/ jans.v13i2.2583 Received: February 23, 2021 Revised: April 27, 2021 Accepted: May 5, 2021

\section{How to Cite}

Kurmana, A. and Srinivas, N. (2021). Quality assessment of compost from Centralized windrow composter (CWC) and Source segregate automatic vessel composter (AVC) at Hyderabad city in India. Journal of Applied and Natural Science, 13(2), 450 - 454. https://doi.org/10.31018/jans.v13i2.2583

\begin{abstract}
Out of the millions of tons of Municipal Solid Waste (MSW) generated annually in India, only about $75-80 \%$ of the waste gets collected and out of this, only $22-28 \%$ is processed and treated, and the remaining is deposited indiscriminately at dump yards. Hyderabad city generates around $5500 \mathrm{MT}$ of waste every day. And only $20 \%$ of the waste is used for composting using the windrow composting process. MSW composting is a rapidly growing method of solid waste management in Hyderabad and In-Vessel composting is the recent initiative by the Govt. of India to reduce the organic solid waste generated at the source. The present study was aimed to assess the degree of accumulation and contamination of the heavy metals in composts from Centralised Windrow Composter (CWC) and Source Segregated Accelerated Vessel Composter (AVC). Compost Samples from CWC and AVC were analysed for metals concentration using Energy Dispersive X-ray Fluorescence Spectrometers (ED$\mathrm{XRF})$. CWC samples were found with slightly high concentrations of heavy metals like Zinc $(0.51-0.66 \%)$, Copper $(0.36-$ $0.45 \%)$, Nickel $0.03-0.05 \%)$, Iron (11.46 - 13.27\%), and chromium ( $0.06-0.14 \%)$ compared to AVC. AVC samples contained high concentrations of Calcium (14.99 - 64.19\%), Potassium $(9.13-29.59 \%)$ and Phosphorous $(1.55-3.43 \%)$ when compared to CWC. The current study does a comparative analysis on the process and nutrients available to assess the quality of the compost from both sources. Considering the above findings source segregated AVC seems to be a better composter than centralised $\mathrm{CWC}$, as the concentrations of $\mathrm{Ca}, \mathrm{K}$, and $\mathrm{P}$ required by the plant were abundant in AVC. Also, considering the process aspect, there is always scope for cross contamination if the waste is separated after treatment which is the case in CWC.
\end{abstract}

Keywords: Compost, Municipal solid waste, Nutrients, Source segregation, Vessel compost

\section{INTRODUCTION}

India stands second to China in the world population, with a population of 1.37 billion, which is equivalent to $17.35 \%$ of today's world population. India's population density is $455 \mathrm{Km}^{2}$ and $34.5 \%$ of the population is in the urban area. Average growth rate stands at $1.15 \%$ annually (World Bank, 2019). Human habitations and their locations in the urban areas are seen increasingly generating economic activities and huge solid waste. Economic development and population growth can also be considered as factors for an increase in waste generation. This can be seen significantly in regions with high population and low- and middle-income countries.
Though we find waste generation rates to vary from nation to nation and within, there is a strong correlation with their per capita income (David, 2015). The economic growth of a country gives a positive correlation with the quality of waste generated when the population of an urbanised nation is also taken into consideration (Rana, 2015). MSW from developing countries indicates that $55-80 \%$ of waste from households and commercial or market area with varying quantities from the street, industries generate $10-30 \%$ of waste (Miezah, 2015).

About 2010 million tons (MT) of MSW was generated in the world during 2016 and by 2050 the numbers would increase and is expected to be around $3400 \mathrm{MT}$, this is 
a huge leap in production to the tune of $70 \%$ within a span of 30 years (Khandelwal, 2019).

India generates 1.5 Lakh tons of MSW per day, which amounts to 56 MT of waste production according to the Ministry of Environment and Forestry (MoEF) and it is further projected to increase to 125 MT by 2031. And according to Swachh Bharat Mission (SBW), roughly 98 percent of the waste generated is collected and 36 percent is treated, and another 33 percent is sent to landfills (Bandela, 2020). In the State of Telangana, it is estimated that about 8360 TPD is collected every day. Nearly 5747 TPD is treated, 869 TPD is going to sanitary landfill and remaining is disposed of in the open Landfill. The door-to-door collection in the State is about $95.9 \%$ (CPCB, 2019). The city of Hyderabad generates 5,500 tonnes of waste daily, 54 per cent of which is biodegradable. GHMC practices centralized as well as decentralized processing of waste. About 16 per cent of waste is sent to landfills (Bandela, 2020).

Food waste, Garden waste, Paper-cardboard and Wood constitutes more than $50 \%$ of the Waste composition which are biodegradable in nature. With the rise in income the biodegradable component declines, countries with the high-income, upper middle-income and lower middle-income have $28 \%, 54 \%$ and $59 \%$ of the biodegradable fraction of MSW (Daniel Hoornweg, 2012).

The cost involved in managing urban waste is too high, which would shoot up the local administrative budget. In developing countries, often local administrative authorities have extremely limited resources and capacities for the management of waste. Due to the poor management of MSW, countries like India still struggles to implement a sustainable model. The current study seeks to assess the degree of accumulation and contamination of the heavy metals in compost from CWC to Source Segregated AVC.

\section{MATERIALS AND METHODS}

A comprehensive study was conducted to assess the quality of the compost, particular with reference to CWC and AVC. The study mainly focused on the composition of nutrients availability, heavy metals of the Source Segregated AVC. In AVC, the main raw material/ biodegradable waste was food waste. AVC is an intuitive technology working on a similar principle to that of Bioreactor where optimal conditions are maintained with several integrally related components (Kumar A., 2015).

\section{Composting reactor}

As claimed by the manufacturer, the AVC processes the food waste in 24 hours. The Unit consists of a decomposition tank to hold the food waste, Rotatory Blades to mix the waste homogeneously. Other parts include air inlet to control the aeration in the unit, Insulator and heater to maintain the required temperature for the micro-organism. There is an exhaust system for moisture to evaporate through the outlet, Deodorise chamber and a fully Automated control system with temperature and moisture monitoring.

\section{Composting materials}

Food waste was segregated and shredded if required into small size based on the Machine type (some composters had blades to break down the food material into smaller pieces). Based on the capacity of the decomposition tank waste was fed into the machine. Sawdust was added to maintain the $\mathrm{C}: \mathrm{N}$ ratio and proprietary bio inoculum which is a mixture of microorganism cultures that accelerates the aerobic composting was added. The machine was run automatically for a period of 24 hours where Blades within the tank stir the contents several times an hour; temperature was automatically maintained by the system. No leachate was produced, and moisture evaporated through the venting system. For volume reduction to take place and compost to come out, the system was shut down for 24 hours to allow the contents to fully process. The material thus removed was placed for curing for 15-20 days before applying to the plants.

\section{Sample}

Site visit were made to various Mechanical Biological Treatment Plants (MBTP), which operated AVC in and around Hyderabad. As part of the New Solid Waste Management Rules 2016, Bulk Generators having 100 $\mathrm{kg}$ and above of waste generation per day shall process and dispose of waste through composting or biomethanation at the source. The aerobic MBTP's located at Commercial Establishment and Residential Areas were selected as sample locations. AVC Samples (SS01, SS02, SS03, and SS04) from a different make of AVC's were collected at MBTP after the curing phase was completed. Curing time for each MBTP differs as per their machine manufactures technology. Moisture, $\mathrm{pH}$ and temperature were measured at the sample site. In addition to these plants, a Compost sample (MSW01, MSW02) from Hyderabad's Integrated Municipal Solid Waste Plant was collected which operates on the Centralised Windrow composting (CWC) method for a comparative study. Below table 1 depicts the details of each MBTP; Location, Sample type, raw material used, Composting time, Amendments, Curing time, operation type.

\section{Analytical methods}

The samples were analysed using Energy Dispersive X-ray Fluorescence Spectrometers (ED-XRF), a nondestructive method of analysis. XRF for Environmental samples has the advantage of being rapid and cost- 
effective. Instead of using the acid digestion method for elemental analysis through this method, Quantitative and qualitative analyses are performed in a very short span (Ene and Georgescu, 2010). The Samples were first sun-dried, followed by drying in a Hot air oven at $110^{\circ} \mathrm{C}$. Pulverized homogeneously and then sieved using $0.2 \mathrm{~mm}$ mesh. A pre-cut polypropylene film was used to hold the finely powdered compost samples in the sample cup. An instrument of make Shimadzu EDX -8000 was used for sample analysis.

\section{Physico-chemical analysis}

Loss of self-heating and general appearance like dark colour, uniformity with the earthy smell is reliable Physical signs of Stability when compared to other parameters. When the temperature of the compost is equal to that of the ambient temperature at this stage, it is believed to be stable. (Chukwujindu, 2006) Sensory evaluation (Smell, Sight and Touch) was done for a few Physical parameters; there is no universally accepted measure for Odour quantification. Its general thumb rules that are reasonable, mature compost have an earthy smell. Mature compost would be dark brown, non-sticky and crumbly to touch. Initially, temperature, $\mathrm{pH}$ and Moisture of the samples were also taken at the MBTP site. For $\mathrm{pH}$ analysis sample was mixed with distilled water at the ratio of $1: 5$ and stirred for 5 minutes, allowed to settle for 10 mins before the $\mathrm{pH}$ of the samples was measured with $\mathrm{pH}$ meter. An infrared thermometer was used to measure the temperature of the samples. Moisture measuring Pin Meter was used to test the moisture of the compost onsite (Table 2).

\section{RESULTS AND DISCUSSION}

\section{Macro nutrients}

The key to sustainable agriculture is soil organic matter management by using composted organic waste. (Mohammad, 2004). High yielding crops require sufficient nutrients like Potassium, Phosphorus and trace elements like copper and Zinc which are essential for plant growth. When compared to the CWC, the decentralised AVC's seems to be having a good percent of macronutrients. This is evident from the reading below. Since for AVC, the raw material was source segregated food waste, and for CWC raw material was a mixed waste. The availability of Potassium (K) was observed to be at a range of 6.89 to $8.56 \%$ for $\mathrm{CWC}$ and 9.13 to $29.59 \%$ for AVC. Phosphorous (P) content was lower at 0.01 to $0.08 \%$ for CWC and 1.55 to $3.43 \%$ for AVC. Sulphur (S) contents were recorded at 3.38 to $3.72 \%$ for CWC and 2.50 to $5.68 \%$ for AVC. Calcium values were exceedingly high in both CWC and AVC, and they were recorded between 30.46 to $36.84 \%$ and 14.99 to $64.19 \%$, respectively (Figure 01 ).

\section{Micro nutrients}

Micronutrients (Trace elements) are essential for plant, animals, and Microorganisms in fewer concentrations, but when applied in excessive, they might dampen the growth reducing the quality of food material by the plant (Rajaie, 2016). The values for Iron ( $\mathrm{Fe}$ ) were in the range of 11.46 to $13.27 \%$ for CWC and 2.25 to 22.36 for AVC. Zine (Zn) availability for the CWC sample was between 0.51 to $0.66 \%$ and 0.14 to $0.34 \%$ for

Table 1. Details of MBTP's used for sampling.

\begin{tabular}{|c|c|c|c|c|c|}
\hline DETAILS & MSW01 & SS01 & SS02 & SS03 & SS04 \\
\hline Location & $\mathrm{HiMSW}^{*}$ & Star Hotel & $\begin{array}{l}\text { Commercial } \\
\text { Trade Centre }\end{array}$ & Food Court & Rythu Bazar \\
\hline Sample Type & MSW & $\begin{array}{l}\text { Source Segre- } \\
\text { gated }\end{array}$ & $\begin{array}{l}\text { Source Seg- } \\
\text { regated }\end{array}$ & $\begin{array}{l}\text { Source Segre- } \\
\text { gated }\end{array}$ & Source Segregated \\
\hline Raw material & Mixed Waste & Food Waste & Food Waste & Food Waste & Vegetable Waste \\
\hline $\begin{array}{l}\text { Initial Composting } \\
\text { Time }\end{array}$ & 33-36 days & 24 Hours & 24 Hours & 24 Hours & 12 Hours \\
\hline Compost Removal & Periodically & $10-15$ days & $24 \mathrm{Hrs}$ & $24 \mathrm{Hrs}$ & $24 \mathrm{Hrs}$ \\
\hline Curing Time & $10-15$ days & $10-15$ days & $7-10$ days & 21 Days & 14 days \\
\hline Operation Type & Manual & Automatic & Automatic & Automatic & Automatic \\
\hline $\begin{array}{l}\text { End to End Pro- } \\
\text { cessing Time }\end{array}$ & 43-52 Days & 15 Days & 10 Days & 21 Days & 14 days \\
\hline
\end{tabular}

*HiMWS - Hyderabad Integrated Municipal Solid Waste Site

Table 2. Physical parameters of the samples collected from MBPT's.

\begin{tabular}{llllll}
\hline Parameters & MSW01 & SS01 & SS02 & SS03 & SS04 \\
\hline Temperature & 37 & 34 & 36 & 41 & 33 \\
$\mathrm{pH}$ & 7 & 8 & 7 & 7 & 8 \\
Colour & Dark Brown & Light Brown & Dark Brown & Dark Brown & Dark Brown \\
Odour & Earthy & Earthy & Earthy & Smokey & Earthy \\
Moisture & Normal & Normal & Medium & Max & Less \\
\hline
\end{tabular}


AVC. Though the availability of Copper (Cu), Manganese (Mn) in CWC were found to be 0.36 to $0.45 \%$ and 0.19 to $0.22 \%$, for AVC the values were very negligible. Nickel (Ni) was only available in the CWC sample. Chromium was present in CWC samples at $0.06 \%$ to $0.14 \%$ and present in the SSO3 sample of AVC. (Figure 2).

\section{Advantages of AVC over CWC}

We can broadly classify the MBT system as two simple concepts; either treat the waste and then separate or segregate the waste and then treat (DEFRA, 2013). Our samples MSW01 \& MSW02 were collected from MBTP operated at a centralised place where waste from different sources was collected and processed without segregation. There might be loss of nutrients through leachate; Leachate is a liquid by-product of compost that contains $\mathrm{N}, \mathrm{P}, \mathrm{K}$, and other trace elements. The concentrations of Marco Nutrients of CWC were less when compared to that of AVC. This was due to concentration loss in leachate. The maximum concentration of $\mathrm{P}$ and $\mathrm{K}$ were found to be $0.08 \%$ and $8.56 \%$ respectively in CWC, whereas in AVC the maximum concentration was $2.67 \%$ and $29.59 \%$. This is because in AVC there was no production of liquid leachate as the composting was done in a controlled manner. Coming to trace elements, the essentiality and toxicity of trace elements by plants and animals vary depending on their species. Therefore, to protect soil fertility and food safety, the most sensitive plant and animal tolerance are to be considered (Epstein, E., 1992). Trace elements like $\mathrm{Zn}, \mathrm{Cu}, \mathrm{Ni}$ concentrations are more in CWC compost which was at $0.66 \%, 0.45 \%$ and $0.03 \%$. These concentrations in AVC are less when compared to CWC. This increase of concentration in CWC can be attributed to cross-contamination of the compost as the waste was separated after treating since mixed waste contains batteries, paint, oil, plastic, and glass, which act as a source for the MSW stream.
The concentration of $\mathrm{Cr}$ was found only in CWC samples at an average of $0.10 \%$. Concentrations of heavy metals and metalloids in the samples are dependent on their presence in the input raw material (Mladenov, 2018). CWC compost raw material was mixed waste gathered as part of the MSW management plan and composted in an open space using Windrow method. In AVC the raw material was Food waste; the organic fraction of waste was segregated and collected at the source by the user. Amendments like Sawdust are used to maintain $\mathrm{C}$ : $\mathrm{N}$ ratio, which was essential for metabolic activity. C: $\mathrm{N}$ utilised by living organism is around 25:1 to 23:1 (Pathak, 2011), which is most desirable for rapid and efficient composting during the aerobic process.

\section{Conclusion}

The present study concluded that compost played a vital role in replenishing nutrients to the depleting soil quality by recycling organic fraction back into the soil. This is an affordable, sustainable, and waste to wealth option in Solid waste management practice. If a proper management system is developed to better utilise the waste, wealth can be automatically created out of it. A centralised system like windrow composting would require huge men and material to manage the composting process, starting from the collection, transportation, waste processing and disposal. This system may invite public dissent due to odour, noise, dust, and land acquisitions to set up such centralised management facilities. Though the study on composting found no adverse effect on a nearby population's health, there is always a concern that open composting would have negative effects on the health of those living in proximity. A decentralised System like source segregated AVC has considerable advantages over the Centralised system to make use of the compost as plant nutrient. It eliminates the multiple steps in the process like collection,

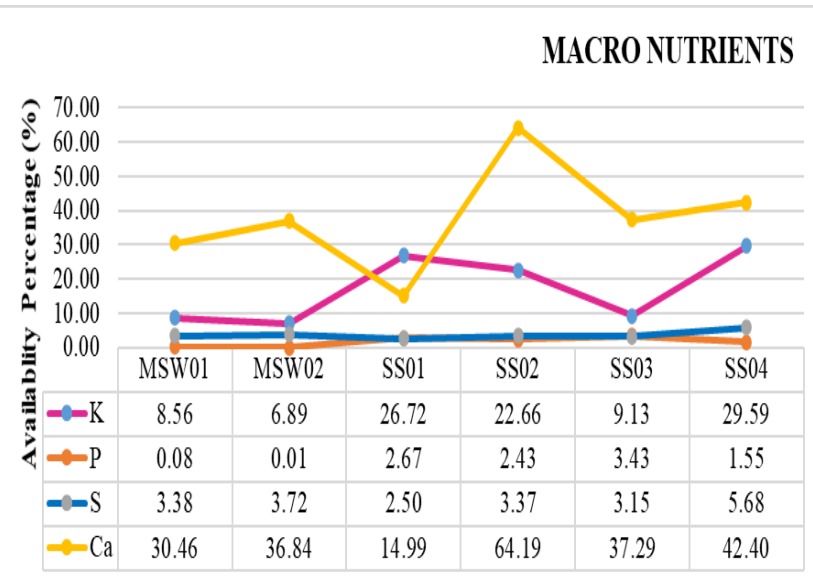

Fig. 1. Macro nutrients availability percent in compost samples.

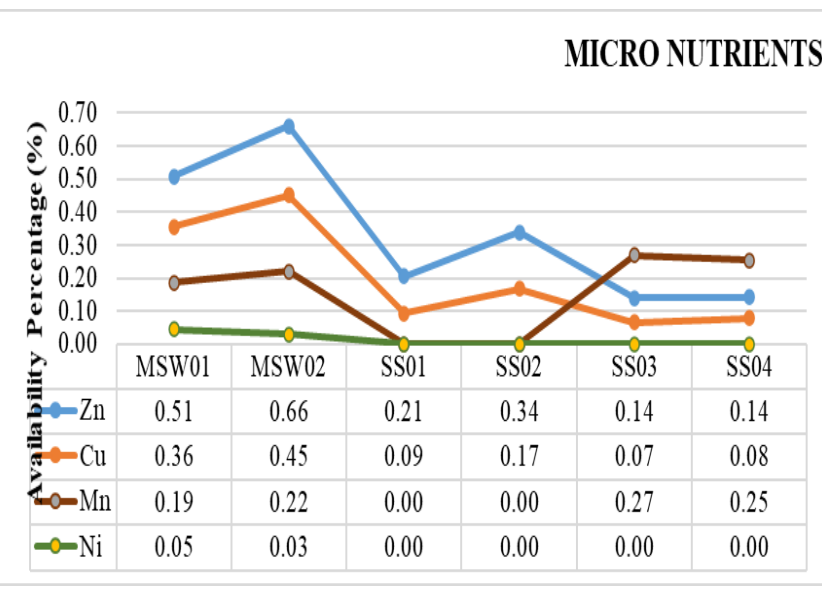

Fig. 2. Micro nutrients availability percent in compost samples. 
Kurmana, A. and Srinivas, N. / J. Appl. \& Nat. Sci. 13(2), 450 - 454 (2021)

transportation, and open disposal and reduces the processing time by $50 \%$. This process outputof the precess has better quality than that of the decentralised system, which manifests from the above observations. Hence, it is imperative to go for such technologies as there is a demand for Quality Compost in India. Best practices require better policies, so based on the analysis and observations made during the study, the following recommendations are made.

- To scale up the production capacity and consumption of AVC, Production Quality protocols needs to be defined for its usage.

- Provide subsidies on the cost of AVC for better reach to the common public.

- Provide incentives/tax rebates for using AVC, which would reduce the financial burden on Govt. infrastructure for collection and transportation of waste.

- Encourage budding entrepreneur to design and develop cost-effective smaller AVC for individual household use, this would encourage composting at the source.

As part of CSR activity, Private institutions can install and maintain such compost plants near parks and commercial establishments where residents can drop wet waste at these centres for further processing.

\section{Conflict of interest}

The authors declare that they have no conflict of interest.

\section{REFERENCES}

1. Pathak, A.K. Singh, M.M and Kumar, V. (2011). Composting of Municipal Solid Waste: A Sustainable Waste Management Technique in Indian Cities - A Review. International Journal of Current Research, 3(12), 339-346. http:// journalcra.com/sites/default/files/issue-pdf/1392_0.pdf

2. Bandela, S D Henam and Dinesh Raj ( 2020). Segregate, Segregate, Segregate: How to make it work for solid waste management. Survey Report, New Delhi, Centre for Science and Environment. https://www.cseindia.org/howgood-are-the-best--10155.

3. Chukwujindu M.A. Iwegbue, A.C Egun, F.N. Emuh and N.O. Isirimah (2006). Compost Maturity Evaluation and its Significance to Agriculture. Pakistan Journal of Biological Sciences, 9(5), 2933-2944. doi:10.3923/pjbs.2006.29 33.2944.

4. CPCB (2019). Annual Report for the year 2018-19 on Implementation of Solid Waste Management Rules. Annual Report, New Delhi: Central Pollution Control Board https://cpcb.nic.in/uploads/MSW/MSW_AnnualReport_20 18-19.pdf

5. Hoornweg, Daniel; Bhada-Tata, Perinaz (2012). What a Waste : A Global Review of Solid Waste Management. Urban development series; knowledge papers no. 15. World Bank, Washington, DC. (c) World Bank. https:// openknowledge.worldbank.org/handle/10986/17388 Li- cense: CC BY 3.0 IGO.

6. David C. Wilson, Ljiljana Rodic, Prasad Modak Reka Soos, Ainhoa Carpintero Rogero, Costas Velis,Mona lyer,Otto Simonett (2015). Global Waste Management Outlook. Vienna, Austria: United Nations Environment Programme (UNEP). https://www.uncclearn.org/wp-conte nt/uploads/library/unep23092015.pdf

7. DEFRA (2013). Mechanical Biological Treatment of Municipal Solid Waste. www.defra.gov.uk, February 27. Accessed October 20, 2020. https://www.gov.uk/ government/publications/mechanical-biological-treatmentof-municipal-solid-waste.

8. Epstein, E. Chaney, R.L. Henry, C. Logan, T.J. (1992). Trace elements in municipal solid waste compost,. Biomass and Bioenergy, 3 (3-4), 227-238. doi:https:// doi.org/10.1016/0961-9534(92)90028-O.

9. Ene, Antoaneta., Alina. Bosneaga Sion, and Lucian. Georgescu (2010). Determination of heavy metals in soils using XRF technique. Romanian Journal of Physics, 55 (7 -8), 815-820. https://rjp.nipne.ro/2010_55_7-8/08 15_0 820.pdf

10. Khandelwal, H., Dhar, H., Thalla, A.K. and Kumar, S. (2019). Application of life cycle assesment in Municipal Soild waste management: A Worldwide Critical Review. Journal of Cleaner Production 209, 630-654. doi:https:// doi.org/10.1016/j.jclepro.2018.10.233

11. Kumar A., Rasappan K. and Santhosh P. (2015). A Pilot scale study on In-Vessel composting of Organic Wasteusing Forced Aeration . Journal of Environmental Research And Development ,10 (2), 239-251.

12. Miezah, K., Obiri-Danso, K., Kadar, Z., Fei-Baffoe, B. and Mensah, M. (2015). Municipal Soild Waste charaterization and quantification as a measure towards effective waste management in Ghana. Waste Management, 46, 15-27. doi: https://doi.org/10.1016/j.wasman.2015.09.009

13. Mladenov, Metodi (2018). Chemical Composition of Different Types of Compost. Journal of Chemical Technology and Metallurgy, 53(4), 712-716. https://dl.uctm.edu/ journal/node/j2018-4/11_18-25_p_712-716.pdf

14. Mohammad H. Golabi, M.J. Denney, and C. Iyekar(2004). Use Of Composted Organic Wastes As Alternative To Synthetic Fertilizers For Enhancing Crop Productivity And Agricultural Sustainability On The Tropical Island Of Guam . International Soil Conservation Organisation Conference. Brisbane: Australian Society of Soil Science Incorported. 1-6. https://www.tucson.ars.ag.gov/isco/isco13/ PAPERS\%20F-L/GOLABI.pdf.

15. Rajaie, M., Tavakoly, A.R. (2016). Effects of municipal waste compost and nitrogen fertilizer on growth and mineral composition of tomato. International Journal of Recycling of Organic Waste in Agriculture, (5), 339-347. doi:https://doi.org/10.1007/s40093-016-0144-4.

16. Rana, R., Ganguly, R and Gupta (2015). An Assessment of solid waste management system in Chandigarh City, India. Electronic Journal of Geotechnicak Engineering, 20, 1547-1572.

17. World Bank (2019). Health Nutrition and Population Statistics: Population estimates and projections. The World Bank Group, 12 18. Accessed December 2019. https:// databank.worldbank.org/source/population-estimates-andprojections\#advancedDownloadOptions. 